\title{
Psychological and physical wellness in older adults from the patient perspective
}

\author{
Sharon Song ${ }^{1}$, Frank J. Prerost ${ }^{2 *}$, Emmanuel Gonzalez ${ }^{3}$, Jonathan Woodin ${ }^{3}$ \\ ${ }^{1}$ Department of Biomedical Sciences, Midwestern University, Downers Grove, USA \\ ${ }^{2}$ Department of Family Medicine, Midwestern University, Downers Grove, USA; ${ }^{*}$ Corresponding Author: fprero@midwestern.edu \\ ${ }^{3}$ Department of Behavioral Medicine, Midwestern University, Downers Grove, USA
}

Received 10 November 2011; revised 22 December 2011; accepted 4 January 2012

\section{ABSTRACT}

The authors of this study examined the relationship between life attitude and physical disease state and found that psychological well being mediated patients' illness course. Coherence and life control were endorsed as the important components of psychological well being. A multi-dimensional measure of life purpose was administered to 97 older adults on the acute rehabilitation unit of a major medical center in the United States. The severity of their illness burden was computed blindly by a physician rater. Regression analysis was conducted to determine if life attitude was predictive of the symptom ratings and factor analysis was performed on the individual items of the life attitude instrument to highlight the psychological profile of the older adults in this study for whom health challenges were primary. There was a significant relationship between life attitude and disease severity, even though the fit of the model indicated the need for other explanatory factors to fully account for sickness. Factor analysis demonstrated that items defined as measuring coherence and life control explained the largest proportion of total variance. Coherence incorporated the logical integration and consistent understanding of one's self and the world at large. Life control referred to volition in decision making, exercising of personal responsibility, and the unfolding of life events. The findings suggested that in older adults undergoing medical hospitalization, psychological resilience had a retrospective orientation rather than prospective. The significant influence of life attitude on patients' physical condition was consistent with clinical observations that the patients who resiliently endure health challenges seem to possess a hardy psychological reserve.
Keywords: Wellness; Illness Burden

\section{INTRODUCTION}

Physicians and psychologists agree that although disease is organic, the mitigating effects of psychological well being have been observed time and again. Some patients present with a cascade of complications and sickness while others overcome medical setbacks with notable resilience. Selye first identified the Hypothalamic-Pituitary-Adrenal axis to explain the body's activation of the immune system in response to stressors [1]. The term psychoneuroimmunology refers to the inseparability of mind and body $[2,3]$. Berczi described Selye's stress syndrome as similar to the neuroimmunoregulatory activation response against infection and injury [4].

The psychobiology of healthy correlates has subsequently become a focus of research interest. Dockray and Steptoe found positive affect to be associated with reduced risk of disease as a result of decreases in cortisol and systemic inflammation with increases in cellular response [5]. Ryff et al. found associations between well being and optimal serum levels of cortisol, norepinephrine, adrenal function, waist-hip ratio, heart function, and high-density cholesterol [6].

Wellness in the general population has been discussed as far back as the middle of the $20^{\text {th }}$ century [7]. The World Health Organization initially described it as "not just the absence of illness but a state of complete physical, mental and social well-being" [8]. The concept has often been equated with purpose in life, well-being, quality of life, psychological hardiness, commitment and challenge, and sense of control [9-12].

Wellness (intended as synonymous to well being) in older adulthood has been conceptualized by various terms. Cowen identified competence, resilience, social systems assimilation, and empowerment as its basic elements [13]. Ryff and Keyes emphasized autonomy, environmental mastery, personal growth, positive interpersonal relationships, purpose in life, and self-acceptance as its six dimensions 
[14]. Mirowsky \& Ross attributed well being to economic prosperity, employment, marriage, children, education, health and physical function, and sense of control [15]. Well being in the context of aging-related disability was defined as the capacity to tolerate adversity and make one's own decisions [16].

Purpose in life was originally conceptualized five decades ago [17]. The construct was first associated with the idea of "will to meaning" where lack of fulfillment of this humanistic need was thought to lead to desperate feelings of emptiness [18]. Its seminal theorist Frankl was a contemporary of those scientists who pioneered the view of mind as biologically connected to body [17].

Purpose in life has been incorporated not only into psychological discussions of well being but it is also endorsed in multidisciplinary contexts including in healthcare. Nearly two decades ago, one oncologist and surgeon emphasized that life experience abundant in meaning and value was essential to staying healthy [19]. A short time later, researchers identified "a sense of meaning and purpose" as a core principle of stress-resilience [20].

The Life Attitude Profile was restructured from two existing measures [7]. It incorporated the Purpose in Life Test and a measure of goal seeking [21]. The approach of integrating existing measures of meaning in life and other aspects of well being (ideally ones standardized and validated for older adults) has been common. For example, it also has suggested that other well being constructs pertinent to older adults include sense of coherence and selftranscendence. Antonovsky conceptualized sense of coherence as healthy tolerance for the exigencies of living because of the innateness of one's world view [22]. Self-transcendence is consistent with Erikson's theory of psychosocial development identifying issues of generativity as arising in older adulthood [23,24]. The method of combining already standardized measures and further simplifying their latent structures has been generally sound and in keeping with measurement theory conventions.

In the current study, the target sample consisted of older adults who were medically hospitalized for serious illnesses. Patients frequently expressed that the helplessness inherent in illness acuity led them to perceive themselves as occupying the "final stage" of life, despite having enjoyed multiple decades of adaptive coping, self-efficacy and successful living in general. They understandably focused on unfulfilled physical needs as if their capacity for a meaningful sense of purpose was diminished.

Evaluating the impact of meaningful sense of purpose, and more broadly well being, on illness state might widen nonpharmacological venues for intervening with afflicted individuals and enhance the benefits to them of allopathic and osteopathic medical care. This study intended to highlight one aspect of older adulthood from a developmental standpoint and in part explain the widespread clinical ob- servation that individuals recovering from major illnesses with a meaningful sense of purpose tend to be healthier physically and have reinforced reasons to live.

\section{METHODOLOGY AND MATERIALS}

\subsection{Participants}

Participants included 97 consenting older adults undergoing inpatient rehabilitation at a medical center in the Midwest metropolitan area in the United States. Their ages ranged between 65 and 97 years. The distribution of their gender was $61 \%$ female and $39 \%$ male. The sample was racially/ethnically representative of the facility's surrounding catchment area. The formation of the target sample occurred independently of the research study since hospital census is determined first by the healthcare needs of the geographical area receiving its services and second according to medical necessity as the primary criteria for acute admission. The sole physiatrist group on medical staff at the facility provided access to consenting patients as part of their endorsement of the project.

The study site was a large 360-bed, full service health care facility that partnered with a medical staff of nearly 500 physicians. Inpatient rehabilitation was provided in a 60-bed independent unit accredited by the Commission on Accreditation of Rehabilitation Facilities (CARF). The medical center has received a number of awards and recognitions for its specialty care including in cerebrovascular disease and total hip replacement.

\subsection{Sampling and Recruitment}

Recruiting of participants occurred on the same afternoon weekly for a period of six months and was facilitated primarily by doctoral clinical psychology students undergoing preparation as clinicians of medically hospitalized older adults. The principal investigators, who were licensed clinical psychologists with staff privileges at the study site, reviewed the weekly census reports and the medical records of individuals newly admitted onto the Acute Rehabilitation unit to determine who was appropriate for the study. Patients undergoing treatment who were at least 65 years in age and had the decisional capacity to give informed consent were included in the target sample and were excluded only if they carried diagnoses of dementia, delirium, cerebrovascular accident, traumatic brain injury, or other central nervous system diseases associated with impairments in cognitive functioning; or if their first language was not English. Random identification numbers decipherable only by a key were assigned to all willing participants. Their involvement was sought during unscheduled therapy time. This study received dual a priori Institutional Review Board approval. 


\subsection{Measures}

The Cumulative Illness Rating Scale for Geriatrics (CIRS$\mathrm{G})$ was a measure of medical illness burden that the consulting physician rated for each patient on the basis of physical exams, review of symptoms, and lab results. The authors of the instrument report good face validity and interrater reliability ranging from 0.78 to 0.88 [25]. Scoring yielded five values; total number of organ systems endorsed as medically burdened, total burden score, ratio of total burden score to the number of organ systems burdened - that yielded a severity index per organ system, and the number of systems at the highest severity ratings of 3 and 4 . The rating options provided at a glance patients' disease state reflecting a few serious problems, multiple problems of mild to moderate severity, and potentially severe problems that warranted the high ratings. The outcome variable from the CIRS-G used in this study was the severity index (total burden score divided by number of organ systems involved).

The Life Attitude Profile (LAP) was a multidimensional measurement of motivation to find meaning and purpose in life [7]. It was comprised of the following subscales: Purpose, Coherence, Existential Emptiness (scored in reverse), Life Control, Goal Seeking Orientation, and Death Acceptance. The scale was a self-report measure eliciting responses along a 7-point Likert scale ranging from "strongly agree" to "strongly disagree." The original validation study indicated satisfactory to very good (i.e. 0.31 to 0.75 ) construct validity [7]

\subsection{Procedures}

As indicated above, participant recruitment was determined on the basis of admission information contained in weekly status reports of patients on the Acute Rehabilitation unit at a large medical center. The research team consisted of a licensed clinical psychologist and clinical psychology doctoral students (receiving course credit) who initiated one-to-one contact with patients during their unscheduled physical, occupational and speech therapy time. Consenting patients were introduced to the study based on a recruitment script that emphasized the voluntary nature of their sought-after participation. They were asked to provide their signature on an IRB-authorized written consent form and then engaged in the administration of the LAP.

After the text edit has been completed, the paper is ready for the template. Duplicate the template file by using the Save As command, and use the naming convention prescribed by your journal for the name of your paper. In this newly created file, highlight all of the contents and import your prepared text file. You are now ready to style your paper.

\subsection{Data Analysis}

The one sample t-test was calculated to establish the significantly higher illness burden of medically-hospitalized older adults relative to healthy individuals and those with mild problems or significant problems in the past. Bivariate regression was computed with the disease severity ratings as the outcome variable and life attitude as predictor. Principal components factor analysis was conducted using SPSS 19.0. The decision on how many factors to retain was based on a comparison between Kaiser's recommendation of eigenvalues over one and the scree plot [26]. Varimax rotation addressed the expectable relatedness of the questionnaire items.

\section{RESULTS}

\subsection{Life Attitude and Disease Severity}

Mean medical illness burden was 2.27 (0.38). The one sample t-test comparing the average of the study sample to the parameter $\mu=0$ reflecting good health indicated that participants in this study had significantly high disease severity, $\mathrm{t}(96)=59.23, p<0.001$. A similar finding was obtained when the comparison was made to the parameter $\mu=1$ for mild symptoms, $\mathrm{t}(96)=33.20, p<0.001$. The extremely low false positive error rate in each computation led to no changes in significance of the overall conclusions even after correcting for the multiple comparisons.

Regression analysis suggested that the effect of life attitude on sickness was small, $\beta=0.24$ but significant nonetheless, $\mathrm{t}(96)=2.40, p<0.05$. Although the total variability of illness burden explained by psychological resilience was $\mathrm{R}^{2}=5.7 \%$, the model was likewise significant, $\mathrm{F}(1,96)=5.75, p<0.05$. Life attitude was an explanatory factor of sickness.

\subsection{Explanatory Factors of IIIness}

Prior to completing the factor analysis, a data cleaning step was required. Of the original 30 survey questions comprising the Life Attitude Profile, there was a high degree of multicollinearity among 12 of them. Table 1 summarizes this potential source of bias. After removing these items, the determinant of the subsequent correlation matrix was 0.027 indicating that the invariably remaining multicollinearity was at an appropriately moderate level to render the factor analysis valid [27]. This value reflected a suitable reduction of the initial determinant computed on the strongly related items that was in the unacceptable range of less than 0.00001. At the same time, Bartlett's test of sphericity $\left(\chi^{2}=315.35, p<0.01\right)$ indicated that the degree of relationship between the questionnaire items was greater than zero (i.e. above the problematically low threshold). The Kaiser-Meyer-Olkin measure of 0.526 suggested that sampling adequacy was achieved.

Seven factors were extracted that accounted for $63.7 \%$ of the total variance. There was a reduction in error of more 


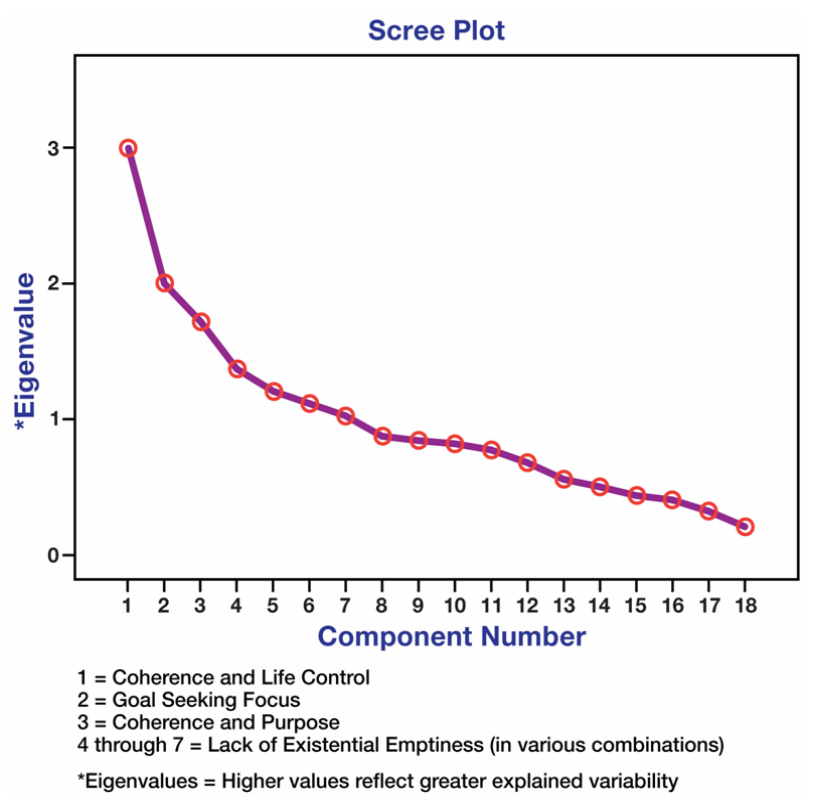

Figure 1. Variability in explanatory factors of illness.

than $13.7 \%$ from the earlier factor analysis. The first extracted component generating the highest eigenvalue of 2.378 following rotation consisted of coherence and life control subscale items on the LAP. Items from the purpose subscale were scattered throughout the first, third, fourth and seventh factors. The Scree plot is displayed in Figure 1.

\section{DISCUSSION}

The significant influence of life attitude on medical illness burden logically follows not only what has been observed clinically in hospitalized patients but also the findings increasingly arising in empirical research. The MIDUS (Midlife Development in the United States) studies have connected proinflammatory markers, namely Interleukin6, cortisol, C-reactive protein and fibrinogen, to stress and aging [28-36]. Researchers have found that chronic and acute stressors (i.e. childhood traumas, parental neglect, difficulties in adulthood, etc.) have generated profiles similar to those of older and oldest adults. A focus on identifying possible mitigating factors of aged proinflammatory markers will contribute to the literature.

Most studies that examine meaningful sense of purpose as a mitigating factor of medical illnesses emphasize strength of character and having a strong will. Much like the tenets of cognitive behavioral theory, their underlying orientation is that empowering thoughts, i.e. "I can get through this," precipitate behavior change. Patient clinical care suggests that psychological resources and physical hardiness are connected physiologically as evidenced by biomarker and neuroplasticity research, which has provided the rationale for this study.
In the field of neuroscience, plasticity refers to the constant state of bodily flux marked by a continual rearrangement of internal relationships secondary to bi-directionality between behaviors and the brain maturation process. It is understood as innate to human functioning. Losing a perceived challenge can deplete testosterone levels; stress modifies the rate of release of cortisol. Differences in experience have influenced disconcordant courses of schizophrenia in identical twins. Neuronal and glial cells potentiate based on the activity of their neighboring cells. Experience alters signaling at a given synapse affecting the number and distribution of neurotransmitter receptors in the postsynaptic region.

Although including a limited number of potential predictor variables, this study did demonstrate what psychologists and physicians have commonly observed in hospital settings that although disease is organic, the mitigating effects of psychological well being are evident. Psychosocial factors provide a context to the way some patients present with a cascade of complications and sickness while others overcome medical setbacks with significant resilience. Neurocognitive reserve is a concept that helps to account for individual differences in the degree of association between physical pathology and the clinical expression of disease, or discrepancies in observed and expected functional impairment [37].

A broader understanding of the influence of psychological resources could enhance how health care is delivered and a healthy status is maintained. Central to traditional medicine are symptoms as the focal point for basing treatment. Although medical education curriculums do incorporate physician-patient communication courses and empirical evidence has demonstrated the impact of a good relationship on treatment efficacy, the promotion of meaningful sense of purpose and other psychological resources is typically embraced subsequent to the detection of depression or related psychiatric symptoms, not preemptively. If there were a diminished illness burden among medically hospitalized patients, it is not unreasonable to envision a decrease in polypharmacy and repeat hospitalizations as eventual outcomes. Greater emphasis on psychological resilience in the older adult stage of life could broaden healthcare perceptions of aging-related illnesses, offset the often downward spiral of polypharmacy, and lessen the prevalence of undiagnosed physical symptoms. Adverse effects related to hospitalizations have generated $\$ 9$ billion in extra costs in as many as $5 \%-10 \%$ of patients with up to $16 \%$ of them being elderly [38]. Up to $30 \%$ of symptoms reported in primary care visits are medically unexplained [39]. Polypharmacy constitutes $9 \%$ of medications among the elderly and is a major risk factor of physical decline, causing added frequent falling and sleep disturbances [40].

In the current research study, meaningful sense of purpose in a sample of medically-ill older adults was comprised 
Table 1. Items removed to reduce statistical bias.

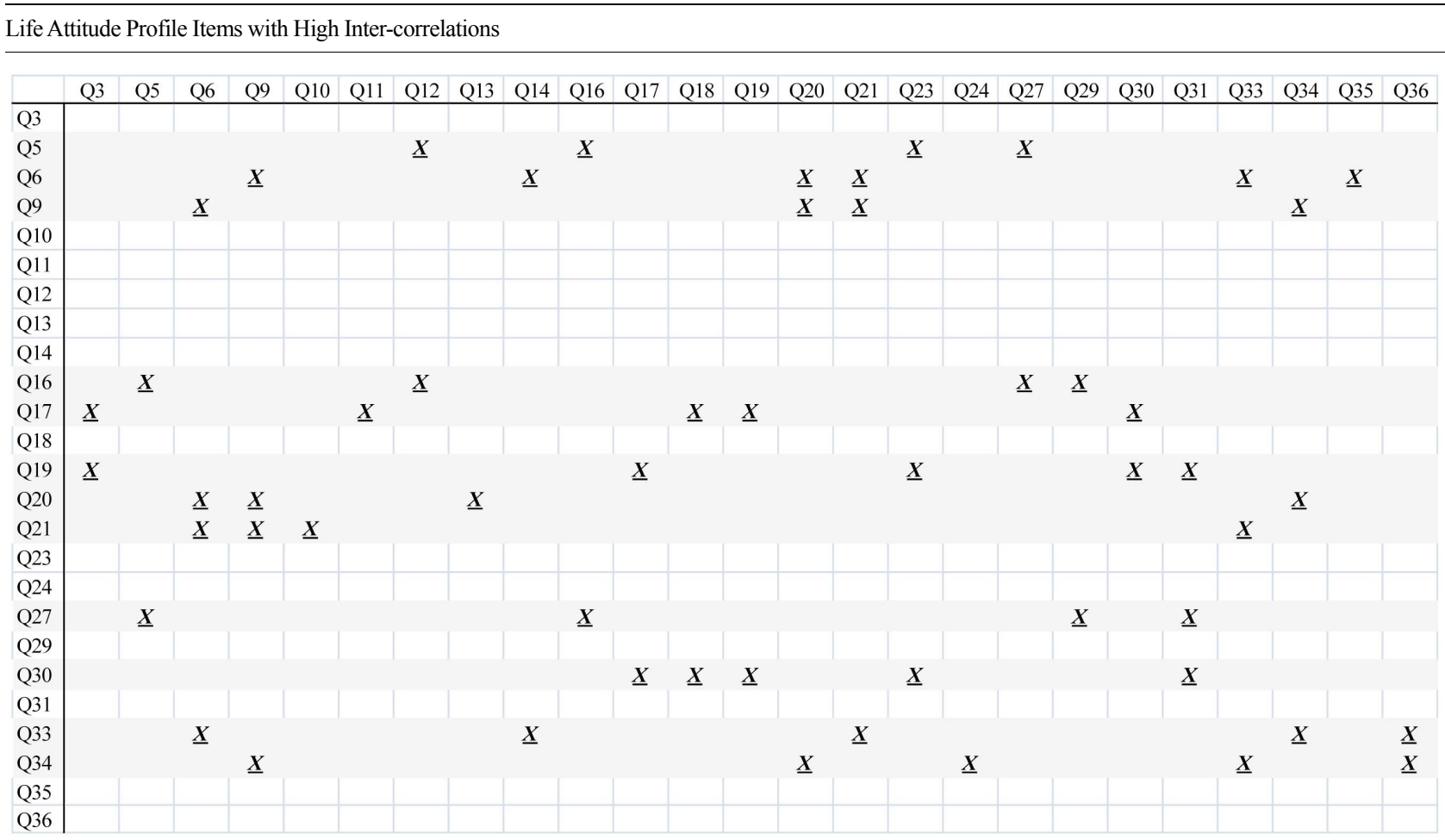

Q3: I regard the opportunity to direct my life as very important

Q5: I have discovered a satisfying life purpose

Q6: I feel that some element which I can't quite define is missing from my life

Q9: I feel the lack of and a need to find a real meaning and purpose in my life

Q10: New and different things appeal to me

Q11: My accomplishments in life are largely determined by my own efforts

Q12: I have been aware of an all powerful and consuming purpose towards which my life has been directed

Q13: I try new activities or areas of interest and then these soon lose their attractiveness

Q14: I would enjoy breaking loose from the routine of life

Q16: I have a philosophy of life that gives my existence significance

Q17: I determine what happens in my life

Q18: Basically, I am living the kind of life I want to live

Q19: Concerning my freedom to make my own choice, I believe I am absolutely free to make all life choices

Q20: I have experienced the feeling that while I am destined to accomplish something important, I cannot put my finger on just what it is

Q21: I am restless

Q23: It is possible for me to live my life in terms of what I want to do

Q24: I feel the need for adventure and "new worlds to conquer"

Q27: In thinking of my life, I see a reason for my being there

Q29: I have a framework that allows me to understand or make sense of my life

Q30: My life is in my hands and I am in control of it

Q31: In achieving life's goals, I have felt completely fulfilled

Q33: I daydream of finding a new place for my life and a new identity

Q34: A new challenge in my life would appeal to me now

Q35: A period of personal hardship and suffering can help give a person a better understanding of the real meaning of life

Q36: I hope for something exciting in the future 
of characteristics and experiences that reflected the uniqueness of their stage of life. Participants commonly minimized the ratings of the statement, "I feel the lack of and a need to find a real meaning in purpose in my life," according to what was for them the realistic view that this advanced psychological need was less salient at the time than during other phases of their lives. However, low scores on the LAP were considered to reflect an immature psyche toward the attainment of growth [41].

To reiterate, the latent factor that had the highest loading in the analysis of the LAP questionnaire items comprised what the existing meaning and purpose measure categorized primarily as "Coherence" and "Life Control." Among the hospitalized older adults the following items were more explanatory and appropriately descriptive of their life stage:

- "I have a philosophy of life that gives my existence significance."

- "I have a framework that allows me to understand or make sense of my life."

- "In thinking of my life, I see a reason for my being here."

- "I have been aware of an all powerful and consuming purpose towards which my life has been directed."

These items differed from the ones listed below that made up the Purpose subscale in the questionnaire. The questions indicating purpose loaded unsystematically onto various factors in our analysis mixing in with not only the Coherence and Life Control subscales but also "Goal Seeking."

- "My past achievements have given my life meaning and purpose."

- "In my life I have very clear goals and aims."

- "Basically, I am living the kind of life I want to live."

- "In achieving life's goals, I have felt completely fulfilled."

- One item did not load onto any factor for the older adults in the research sample:

- "I know where my life is going in the future."

The researchers involved in the data collection phase of the project frequently had the opportunity to gather information about the rationales for the answers that participants provided. What was learned was that the presence of major medical illness often confounded their responses. Patients commonly expressed, "I would have agreed more with that statement before this happened [referring to their sickness]," and, "I used to feel that was true when I was young."

Future research will make a contribution if a range of psychological and physiological variables can be included in the regression model attempting to explain medical illness burden. Prominent physical ones known to most health care providers are family and medical history together with nicotine usage. Important psychological ex- planatory factors have been typically comprised of mental health state, personality styles, and temperament. The benefit of such an empirically and clinically based approach might enhance explanations of the interworking of mind and body. A behavioral interpretation of neural plasticity, the expansions and reductions of connections in the neurons and glial cells influenced by one's experiences that perpetually reinforces resiliency and acquisition of adaptive behaviors as a result of those internal processes, could be developed.

Limitations of this study included a potential for bias in the target sample since participants were recruited from an inpatient rehabilitation unit in a single medical center in the Chicago metropolitan, Illinois area. Older adults in the surrounding community tended to practice devout $\mathrm{Ca}$ tholicism and be homogenously of the lower middle class socioeconomic strata. Many of the patients possessed unfailing resilience in the face of major medical illness because it was consistent with their religious beliefs. It is possible that atheist or agnostic participants might not endorse items of coherence and life control for which the emphasis is on psychological wholeness and an understanding of life beyond themselves; unfortunately, religious background was not controlled for as part of this study. It was the clinical observation of the principal investigators that the patients who comprised the target sample were inclined to experience luxury in life defined by material standards of a disparate nature compared to their upper and upper middle class counterparts. Their mindset that psychological resources were the equivalent of their own internal riches might have been more characteristic of their specific cohort which could limit the generalizability of the findings to the broader population.

Other limitations included the relatively small sample size for the factor analysis. Although sampling adequacy was established statistically, purist statisticians have been known to define minimum sample sizes of 300 and 500 as appropriate. At very smallest, five to ten participants per variable has typically been recommended. In the current study, there were 5.3 participants per question. Nonetheless, this study accomplished one of the researchers' intent to suggest that sense of purpose in older adults might be influenced by a developmental progression that is often not well understood.

According to the US Census Bureau Decennial Census Projections more than 35 million Americans are age 65 years and older; by 2050 this figure is estimated to double to 70 million. Individuals in the fastest growing age group are 85 years and older and comprise 4.5 million of the population; it is estimated that by 2050 there will be more than 21 million approaching their ninth decade of life as a result of the significantly lengthened life span [42]. Currently, one out of every nine American is considered an older adult. 
In our society, older adults tend to be marginalized. Ageism exists because inherent in the human condition is a fear of growing older to the point of lacking the capacity to sustain oneself. Misconceptions include the portrayal of older adults as isolated, depressed, unable to cope, cognitively impaired, and dependent on others. Assumptions are made that depression is a natural part of aging; complaints about memory are indicative of dementia; and older adults who are vital and living well are exceptions rather than the rule [43].

By expanding current research of older adults, the investigators intended not only to broaden understanding of the psychological functioning of seniors but also to disseminate information that will debunk myths and facilitate the view that older adulthood has its rewards and challenges much like each of the stages of life that precede it. It is the intent of the investigators of the current study to seek out research and intervention methods that enhance quality of life in older adults to reduce healthcare costs and respond holistically to the aging of America.

\section{ACKNOWLEDGEMENTS}

The authors would like to thank Drs. William Davison, Peter Blendonohy, Stephen Talty, and Christopher Pasquale of Resurrection Medical Center for their assistance in conducting this research study, and Dr. Dennis Paulson of Midwestern University for his collegial support. Funding for this project was provided through the Midwestern University start up funds.

\section{REFERENCES}

[1] Selye, H. (1946) The general adaptation syndrome and the diseases of adaptation. Journal of Clinical Endocrinology, 6, 117-230. doi:10.1210/jcem-6-2-117

[2] Solomon, G.F. and Moos, R.H. (1964) Emotions, immunity, and disease: A speculative theoretical integration. Archives of General Psychiatry, 11, 657-674. doi:10.1001/archpsyc.1964.01720300087011

[3] Christiansen, C. (2007) Adolf Meyer revisited: Connections between lifestyles, resilience and illness. Journal of Occupational Science, 14, 63-76. doi:10.1080/14427591.2007.9686586

[4] Berczi, I. (1998) The stress concept and neuroimmunoregulation in modern biology. Annals New York Academy of Sciences, 851, 3-12. doi:10.1111/j.1749-6632.1998.tb08969.x

[5] Dockray, S. and Steptoe, A. (2010) Positive affect and psychobiological processes. Neuroscience and Biobehavioral Reviews, 35, 69-75. doi:10.1016/j.neubiorev.2010.01.006

[6] Ryff, C.D., Love, G.D., Urry, H.L., Muller, D., Rosenkranz, M.A., Friedman, E.M., Davidson, R.J. and Singer, B. (2006) Psychological well-being and ill-being: Do they have distinct or mirrored biological correlates? Psychotherapy and Psychomatics, 75, 85-95.

\section{doi:10.1159/000090892}

[7] Reker, G.T. and Peacock, E.J. (1981) The life attitude profile (LAP): A multidimensional instrument for assessing attitudes toward life. Canadian Journal of Behavioral Science, 13, 264-273. doi:10.1037/h0081178

[8] World Health Organization (1967) Health promotion glossary. Constitution of the World Health Organization, Geneva.

[9] Roscoe, L.J. (2009) Wellness: A review of theory and measurement of counselors. Journal of Counseling \& Development, 87, 216-226. doi:10.1002/j.1556-6678.2009.tb00570.x

[10] Maddi, S.R. (2005) On hardiness and other pathways to resilience. American Psychologist, 60, 261-262. doi:10.1037/0003-066X.60.3.261

[11] Fisher, J.W., Francis, L.J. and Johnson, P. (2000) Assessing spiritual health via four domains of spiritual wellbeing: The SH4DI. Pastoral Psychology, 49, 133-145. doi:10.1023/A:1004609227002

[12] Sperry, L. (1992) Recent developments in neuroscience, behavioral medicine, and psychoneuroommunology: Implications for physical and psychological well-being. Individual Psychology, 48, 480-487.

[13] Cowen, E.L. (1991) In pursuit of wellness. American Psychologist, 46, 404-408. doi:10.1037/0003-066X.46.4.404

[14] Ryff, C.D. and Keyes, C.L.M. (1995) The structure of psychological well-being revisited. Journal of Personality and Social Psychology, 69, 719-727. doi:10.1037/0022-3514.69.4.719

[15] Mirowsky, J. and Ross, C. (2010) Well being across the life course. In: Horwitz, A.V., Ed., A Handbook for the Study of Mental Health: Social Contexts, Theories, and Systems, Cambridge University Press, New Brunswick, 361-383.

[16] Yorkston, K.M., McMullan, K.A., Molton, I. and Jensen, M.P. (2010) Pathways of change experienced by people aging with disability: A focus group study. Disability and Rehabilitation, 32, 1697-1704. doi:10.3109/09638281003678317

[17] Frankl, V.E. (1963) Man's search for meaning. Washington Square Press, New York.

[18] Nygren, B., Aléx, L., Jonsén, E., Gustafson, Y., Norberg, A. and Lundman, B. (2005) Resilience, a sense of coherence, purpose in life and self-transcendence in relation to perceived physical and mental health among the oldest old. Aging \& Mental Health, 9, 354-362. doi:10.1080/1360500114415

[19] Siegel, B.S. (1990) Love, medicine and miracle: Lessons learned about self-healing from a surgeon's experience with exceptional patients. Harper Collins Publishers Inc., New York.

[20] Hafen, B.Q., Karren, K.J., Frandsen, K.J. and Smith, N.L. (1996) Mind/body health: The effects of attitudes, emotions, and relationships. Allyn \& Bacon Publishers Inc., Needham Heights.

[21] Crumbaugh, J.C. and Maholich, L.T. (1969) An experi- 
mental study in existentialism: The psychometric approach to Frankl's concepts. Journal of Clinical Psychology, 20, 200-207. doi:10.1002/1097-4679(196404)20:2<200::AID-JCLP22 70200203>3.0.CO;2-U

[22] Antonovsky, A. (1993) The structure and properties of the sense of coherence scale. Social Science \& Medicine, 36, 725-733. doi:10.1016/0277-9536(93)90033-Z

[23] Reed, P.G. (1991) Self-transcendence and mental health in oldest-old adults. Nursing Research, 40, 5-11. doi:10.1097/00006199-199101000-00002

[24] Erikson, E.H. (1980) Identity and the life cycle. W.W. Norton \& Company, New York.

[25] Miller, M.D., Paradis, C.F., Houck, P.R., Mazumdar, S., Stack, J.A., Rifai, A.H., Mulsant, B. and Reynolds, C.F. (1992) Rating chronic medical illness burden in geropsychiatric practice and research: Application of the Cumulative Illness Rating Scale. Psychiatry Research, 41, 237248. doi:10.1016/0165-1781(92)90005-N

[26] Costello, A.B. and Osborne, J.W. (2005) Best practices in exploratory factor analysis: Four recommendations for getting the most from your analysis. Practical Assessment, Research and Evaluation, 10, 1-9.

[27] Field, A.P. (2005) Discovering statistics using SPSS. 2nd Edition, Sage Publications, London.

[28] Almeida, D., Seltzer, M., Greenberg, J., Savla, J., Stawski, R., Hong, J. and Taylor, J. (2009) Psychosocial and biological markers of daily lives of midlife parents of children with disabilities. Journal of Health and Social Behavior, 50, 1-15.

[29] Charles, S.T., Almeida, D.M., Neupert, S.D., Schaie, K.W. and Abeles, R.P. (2008) Assessing health behaviors across individuals, situations, and time. In: Abeles, R.P. and Schaie, K.W., Eds., Social Structures and Aging Individuals: Continuing Challenges, Springer, New York.

[30] McGonagle, K., King, H. and Almeida, D. (2009) Assessing daily stress processes in social surveys by combining stressor exposure and salivary cortisol. Biodemography and Social Biology, 55, 219-237. doi:10.1080/19485560903382338

[31] Meyer, J., Cifuentes, M.M. and Warren, N. (2011) Association of self-rated physical health and incident hypertension with O*NET factors: Validation using a representative national survey. Journal of Occupational and Environmental Medicine, 53, 139-145. doi:10.1097/JOM.0b013e318203f220

[32] Morozink, J.A., Friedman, E.M., Coe, C.L. and Ryff, C.D. (2010) Socioeconomic and psychosocial predictors of Interleukin-6 in the MIDUS national sample. Health Psychology, 29, 626-635. doi:10.1037/a0021360
[33] Piazza, J.R., Almeida, D.M., Dmitrieva, N.O. and Klein, L.C. (2010) Frontiers in the use of biomarkers of health in research on stress and aging. Journals of Gerontology, Series B: Psychological Sciences and Social Sciences, 65, 513-525. doi:10.1093/geronb/gbq049

[34] Seeman, T.E., Love, G.D., Weinstein, M. and Ryff, C.D. (2010) Bioindicators in the MIDUS national study: Protocol, measures, sample, and comparative context. Journal of Aging and Health, 22, 1059-1080. doi:10.1177/0898264310374355

[35] Seltzer, M.M., Abbeduto, L., Greenberg, J.S., Almeida, D.M., Witt, W. and Glidden, L.M. (2009) Chapter 7: Biomarkers in the study of families of children with developmental disabilities. In Seltzer, M.M. and Glidden, L.M., Eds., International Review of Research in Mental Retardation, Academic Press, New York, 213-249.

[36] Slopen, N., Lewis, T.T., Gruenewald, T.L., Mujahid, M.S., Ryff, C.D., Albert, M.A. and Williams, D.R. (2010) Early life adversity and inflammation in African Americans and Whites in the midlife in the United States survey. Psychosomatic Medicine, 42, 694-701. doi:10.1097/PSY.0b013e3181e9c16f

[37] Jones, R., Fong, T., Metzger, E., Tulebaev, S., Yang, F., Alsop, D., Marcantonio, E., Cupples, L., Gottlieb, G. and Inouye, S. (2010) Aging, brain disease, and reserve: Implications for delirium. American Journal of Geriatric Psychiatry, 18, 117-127. doi:10.1097/JGP.0b013e3181b972e8

[38] Shan, C. and Miller, M. (2003) Excess length of stay, charges, and mortality attributable to medical injuries during hospitalization. Journal of the American Medical Association, 290, 1869-1874.

[39] Kroenke, K. and Price, K. (1993) Symptoms in the community, prevalence, classification and psychiatric comorbidity. Archives of Internal Medicine, 153, 2472-2485. doi:10.1001/archinte.1993.00410210102011

[40] Kim, J., Tofade, T. and Peckman, H. (2009) Caring for the elderly in an inpatient setting: Managing insomnia and polypharmacy. Journal of Pharmacy Practice, 22, 494-506. doi:10.1177/0897190008330199

[41] Maslow, A.H. (1970) Motivation and Personality. 3rd Edition, Harper \& Row, New York.

[42] United States Census Bureau (2008) Decennial Census Projections [Summary tables]. http://www.census.gov/population/www/projections/sum mary tables.html

[43] Daniel, J.H., Roysicar, G., Abeles, N. and Boyd, C. (2004) Individual and cultural diversity competency: Focus on the therapist. Journal of Clinical Psychology, 60, 755770. doi:10.1002/jclp.20014 